\title{
PREDIKSI NILAI AKADEMIK MAHASISWA MENGGUNAKAN ALGORITMA NAIIVE BAYES
}

\author{
R. Annisa ${ }^{1}$, A. Sasongko² \\ ${ }^{1}$ Universitas Bina Sarana Informatika \\ Indonesia \\ ${ }^{2}$ Universitas Bina Sarana Informatika \\ Indonesia \\ e-mail: riski.mc@bsi.ac.id, sasongko45@gmail.com
}

\begin{abstract}
Abstrak
Pendidikan adalah suatu hal yang sangat penting dalam perkembangan suatu negara. Salah satu cara untuk meningkatkan kualitas yang lebih tinggi dari skema pendidikan tinggi adalah dengan memprediksi penilaian akademik mahasiswa dan dengan demikian lembaga dapat mengambil tindakan awal untuk meningkatkan kinerja siswa. Klasifikasi mahasiswa berdasarkan potensi kinerja akademis mereka dapat menjadi strategi yang berguna untuk mengurangi kegagalan, untuk mempromosikan pencapaian hasil yang lebih baik dan untuk mengelola sumber daya yang lebih baik di lembaga pendidikan tinggi. Penelitian ini akan mengukur nilai akademis mahasiswa dengan menggunakan algoritma Naïve Bayes dimana memanfaatkan perhitungan probabilitas dan statistik data sebelumnya untuk memprediksi data di masa depan berdasarkan pada data sebelumnya. Hasil penelitian menunjukkan accuracy $96,24 \%$, precison $95,76 \%$, dan recall $100 \%$. Selain itu dengan algoritma Naïve Bayes menunjukkan hasil prediksi berdasarkan mahasiswa yang kuliah sambil bekerja, jadwal kerja mahasiswa, dan berdasarkan waktu kuliah.
\end{abstract}

Kata kunci: Pendidikan, Akademik, Naïve Bayes

\begin{abstract}
Education is very important in the development of a country. One way to improve the higher quality of improving tertiary education is to predict student academics and thus the institution can take initial action to improve students. Classification of students based on their academic potential can be a useful strategy to reduce problems, to support better outcomes, and to better manage resources in higher education institutions. This study will measure the academic value used by students using the Naïve Bayes algorithm, which uses calculations and statistical data to predict future data based on previous data. The results showed an accuracy of 96.24\%, 95.76\% precision, and $100 \%$ recall. Also, Naïve Bayes shows prediction results based on students who are working, student work schedules, and based on lecture time.
\end{abstract}

Keywords : Education, Academic, Naïve Bayes

\section{PENDAHULUAN}

Pendidikan merupakan kegiatan terencana yang berlangsung sepanjang hidup dan menjadi kebutuhan bagi manusia. Pendidikan tidak hanya berlangsung di sekolah, akan tetapi dapat juga berlangsung di dalam keluarga dan masyarakat. Oleh karena itu, pendidikan menjadi tanggung jawab bersama antara keluarga, masyarakat, dan juga pemerintah. Pendidikan memegang peranan penting bagi kehidupan manusia. Tanpa pendidikan manusia akan sulit berkembang atau bahkan tidak berkembang. Dengan demikian, pendidikan harus benar benar diarahkan agar menghasilkan manusia yang berkembang dan berkualitas serta mampu 
bersaing, di samping memiliki akhlak dan moral yang baik (Ayuwanti, 2016).

Pendidikan adalah suatu hal yang sangat penting dalam perkembangan suatu negara. Tujuan utama dari institusi pendidikan tinggi adalah untuk menghadirkan pendidikan yang berkualitas kepada para siswanya. Salah satu cara untuk meningkatkan kualitas yang lebih tinggi dari skema pendidikan tinggi adalah dengan memprediksi penilaian akademik siswa dan dengan demikian lembaga dapat mengambil tindakan awal untuk meningkatkan kinerja siswa dan kualitas pengajaran yang ada (Hamsa, Indiradevi, \& Kizhakkethottam, 2016).

Pendidikan itu sebenarnya harus didapatkan oleh setiap lapisan masyarakat agar pembangunan suatu bangsa dan negara itu dapat berjalan dengan baik. Hal tersebut juga terlihat dalam UUD 1945 pasal 31 yang menyatakan bahwa setiap warga negara berhak mendapatkan pendidikan (Amandemen UUD 1945, Bab XIII tentang Pendidikan dan Ke budayaan). Pernyataan dalam pasal 31 itu sekaligus merupakan landasan dan jaminan bagi setiap warga negara Indonesia untuk memperoleh pendidikan tanpa membedakan suku, agama, dan golongan (Sirait, 2016).

Guney (2009) menyatakan bahwa penelitian tentang kinerja akademik mahasiswa adalah topik penting dalam dunia pendidikan. Menemukan faktorfaktor yang berpengaruh terhadap kinerja akademik mahasiswa adalah hal yang sangat penting bagi universitas, dosen dan dalam beberapa hal untuk mahasiswa sendiri. Faktor tersebut akan sangat berpengaruh terhadap kebijakan akademik universitas, perbaikan terhadap kurikulum, penilaian kinerja dosen dan modifikasi cara dosen dalam mengajar (Wijaya, 2012).

Selain itu, penilaian standar juga dapat digunakan untuk membantu mengidentifikasi kekuatan dan kelemahan siswa dalam berbagai kemampuan intelektual, dan untuk membuat proyeksi tentang penilaian masa depan siswa. Dengan mengizinkan penyediaan pendidikan yang sesuai dengan kebutuhan siswa dibuat berdasarkan prestasi saat ini dan kemungkinan penilaian akademik siswa (Mandelman, Barbot, \& Grigorenko, 2015).

Algoritma adalah metode efektif yang diekspresikan sebagai rangkaian terbatas. Algoritma juga merupakan kumpulan perintah untuk menyelesaikan suatu masalah. Perintahperintah ini dapat diterjemahkan secara bertahap dari awal hingga akhir. Masalah tersebut dapat berupa apa saja, dengan syarat untuk setiap permasalahan memiliki kriteria kondisi awal yang harus dipenuhi sebelum menjalankan sebuah algoritma. Algoritma juga memiliki pengulangan proses (iterasi), dan juga memiliki keputusan hingga keputusan selesai (Maulana, 2017).

Machine Learning (ML) adalah salah satu metodologi cerdas yang telah menunjukkan hasil yang menjanjikan dalam domain klasifikasi dan prediksi. Salah satu tugas ML secara umum melibatkan memprediksi variabel target dalam data yang sebelumnya tidak terlihat, adalah klasifikasi. Tujuan klasifikasi adalah untuk memprediksi variabel target (kelas) dengan membangun model klasifikasi berdasarkan pada dataset pelatihan, dan kemudian menggunakan model itu untuk memprediksi nilai kelas data uji (Bunker \& Thabtah, 2019)

Klasifikasi awal mahasiswa berdasarkan potensi kinerja akademis mereka dapat menjadi strategi yang berguna untuk mengurangi kegagalan, untuk mempromosikan pencapaian hasil yang lebih baik dan untuk mengelola sumber daya yang lebih baik di lembaga pendidikan tinggi. Hal ini dapat menghasilkan desain tindakan yang berbeda yang menargetkan kelompok siswa yang berbeda sesuai dengan potensi mereka dan juga dapat menghasilkan alokasi sumber daya lembaga yang lebih efisien (Miguéis, Freitas, Garcia, \& Silva, 2018).

Pada penelitian ini akan mengukur nilai akademis mahasiswa dengan menggunakan algoritma Naïve Bayes dengan memanfaatkan perhitungan probabilitas dan statistik data sebelumnya 
untuk memprediksi data di masa depan berdasarkan pada data sebelumnya.

\section{METODE}

\section{Klasifikasi}

Metode Klasifikasi adalah jenis analisis data yang dapat membantu orang memprediksi label kelas sampel harus diklasifikasikan. Berbagai macam teknik klasifikasi telah diusulkan dalam bidangbidang seperti pembelajaran mesin, sistem pakar dan statistik. Sejak beberapa tahun yang lalu peneliti telah mengembangkan repositori software untuk lebih dalam megenal data, dari dua puluh metode klasifikasi, Naïve Bayes merupakan salah satu metode klasifikasi terbaik (Annisa, 2019).

\section{Naïve Bayes}

Naïve Bayes didasarkan pada teorema Bayes. Oleh karena itu, meninjau teorema Bayes dan kemudian menggambarkan klasifikasi. List dari paket software data mining yang mendukung pembelajaran klasifikasi Naïve Bayes tersedia. Beberapa aplikasi klasifikasi Naïve Bayes tersedia dengan referensi (Brown, 2014). Teorema Bayes berasal dari persamaan 1:

$$
P(A \mid B)=\frac{P(B \mid A) P(A)}{P(B)}
$$

$P(A \mid B)$ : Probabilitas kondisional dari kejadian $A$ yang terjadi mengingat kejadian $B$

$P(A) \quad$ : Probabilitas kejadian A terjadi

$P(B) \quad$ : Probabilitas kejadian B terjadi

$P(B \mid A)$ : Probabilitas kondisional dari kejadian $B$ yang terjadi mengingat kejadian $A$

Klasifikasi Naïve Bayes memperkirakan persamaan probabilitas sesuai:

$$
\begin{gathered}
P(y)=\frac{n_{y}}{n} \\
P\left(x_{i} \mid y\right)=\frac{n_{y \& x_{i}}}{n_{y}}
\end{gathered}
$$

Keterangan:

$n$ : total nomor dari point data pada data set training,

$n_{y} \quad$ : nomor dari point data target class y

$n_{y \& x_{i}}$ : nomor dari point data dengan target class y

$i \quad$ : variabel atribut yang mengambil nilai dari $x_{i}$

Hipotesis $\mathrm{H}$ dan bukti $\mathrm{E}$ diberikan dan Teorema Bayes menyatakan bahwa hubungan antara probabilitas Hipotesis sebelum mendapatkan bukti $P(H)$ dan probabilitas hipotesis setelah mendapatkan bukti $P(H \mid E)$ adalah:

$$
P(H \mid E)=\frac{P(E \mid H) P(H)}{P(E)}
$$

Tujuan utama Teorema Bayes adalah untuk menghitung probabilitas bersyarat. Aturan Bayes dapat diturunkan dari dua persamaan berikut:

$$
P(A \mid B)=\frac{P(A \cap B)}{P(B)}
$$

Persamaan di bawah ini mewakili probabilitas bersyarat dari $A$, mengingat $\mathrm{B}$ :

$$
P(B \mid A)=\frac{P(B \cap A)}{P(A)}
$$

Oleh karena itu, pada penggabungan dua persamaan di atas kita mendapatkan Teorema Bayes.

Persamaan di atas adalah untuk variabel prediktor tunggal, namun, dalam aplikasi dunia nyata, ada lebih dari satu variabel prediktor dan untuk masalah klasifikasi, ada lebih dari satu kelas output. Kelas-kelas dapat direpresentasikan sebagai, C1, C2, ..., Ck dan variabel prediktor dapat direpresentasikan sebagai vektor, x1, x2, ..., xn.

Tujuan dari algoritma Naïve Bayes adalah untuk mengukur probabilitas bersyarat dari suatu peristiwa dengan vektor fitur x1, x2, .., xn milik kelas $\mathrm{Ci}$ tertentu, 
$P\left(C_{i} \mid x_{1}, x_{2}, \ldots, x_{n}\right)=$

$\frac{P\left(x_{1}, x_{2, \ldots,}, x_{n} \mid C_{i}\right) \cdot P\left(C_{i}\right)}{P\left(x_{1}, x_{2} \ldots, x_{n}\right)}$ for $1<i<k$

Namun, probabilitas bersyarat, yaitu, $P\left(x_{j} \mid x_{j}+1, \ldots, x_{n}, c_{i}\right.$ diringkas menjadi $P\left(x_{j} \mid c_{i}\right)$ karena setiap variabel prediktor independen di Naïve Bayes. Persamaan terakhir adalah:

$P\left(C_{i} \mid x_{1}, x_{2} \ldots, x_{n}\right)=$

$\prod_{j=1}^{j=n} P\left(x_{j} \mid C_{i}\right) \cdot \frac{P\left(C_{i}\right)}{P\left(x_{1}, x_{2} \ldots, x_{n}\right)}$ for $1<i<k$

Di sini, $P(x 1, x 2, \ldots, x n)$ adalah konstan untuk semua kelas, oleh karena itu kita mendapatkan:

$P\left(C_{i} \mid x_{1}, x_{2} \ldots, x_{n}\right)=$

$\alpha\left(\prod_{j=1}^{j=n} P\left(x_{j} \mid C_{i}\right)\right) \cdot P\left(C_{i}\right)$ for $1<i<k$

\section{Datasets}

Pada penelitian ini menggunakan data mahasiswa Universitas Bina Sarana
Informatika wilayah 3 yaitu kampus BSI wilayah jawa tengah yaitu wilayah Yogyakarta, Purwokerto, Semarang, dan Solo. Datasets mempunyai 15 atribut yang terdiri dari data nominal dan numerik.

Pada penelitian ini tahap pembersihan data tidak dilakukan karna umumnya data pada database Nilai Akademik Mahasiswa Universitas Bina Sarana Informatika sudah tidak ada duplikasi, kesalahan, dan validation rules pada database sudah sesuai dengan penelitian. Datasets berisi atribut sebagai berikut: nim, gelombang, wilayah, umur, semester, nama jurusan, kuliah sambil kerja, jadwal kerja, waktu kuliah, ip semester 1 , ip semester 2, ip semester 3 , ip semester 4, ip semester 5, indeks prestasi komulatif, melaksanakan tugas akhir. Selanjutnya untuk validasi menggunakan 10 -fold cross validation dengan membagi data training sebesar $70 \%$ dan data testing sebesar $30 \%$. Hasil pengukuran menghasilkan Tabel 1 confusion matrix yang dapat menghasilkan perhitungan accuracy, tingkat error, sensitivity, spesificity, precision, dan recall.

Tabel 1. Confusion Matrix

\begin{tabular}{ccc}
\hline & Actual True & Actual False \\
\hline Predicted True & True Positive $(T P)$ & False Negative $(F N)$ \\
Predicted False & False Positive (FP) & True Negative $(T N)$ \\
\hline
\end{tabular}

Formulasi perhitungan adalah sebagai berikut:

$$
\begin{gathered}
\text { Accuracy }=\frac{T P+T N}{T P+F N+F P+T N} \\
\text { Sensitivity }=\text { recall }=T P_{\text {rate }}=\frac{T P}{T P+F N} \\
\text { Spesificity }=T N_{\text {rate }}=\frac{T N}{T N+F P} \\
F P_{\text {rate }}=\frac{F P}{F P+T N} \\
\text { Precision }=\frac{T P}{T P+F P} \\
F \text { Measure }=\frac{2 R P}{R+P} \\
G-\text { Mean }=\sqrt{\text { sensitivity } * \text { specificity }} \\
\text { Error }=1-\text { Accuracy }
\end{gathered}
$$

\section{HASIL DAN PEMBAHASAN}

Pada penelitian ini dilakukan eksperimen dengan menggunakan komputer untuk melakukan proses perhitungan terhadap metode yang digunakan yaitu metode klasifikasi Naïve Bayes. Spesifikasi perangkat keras dan sistem operasi yang digunakan pada penelitian ini adalah menggunakan sebuah laptop DELL dengan prosessor Intel(R) Core(TM) i5-3340M CPU @ 2.70GHz, memori (RAM) 4,00 GB, dan menggunakan sistem operasi Windows 10 Pro 64-bit. Sedangkan tools yang digunakan pada penelitian ini adalah Rstudio.

Rancangan penelitian ini menggunakan dataset yang terdiri dari 
619 data dan 15 atribut yang terdiri dari data numerik dan nominal. Langkah- langkah penelitian ditunjukkan pada Gambar 1:

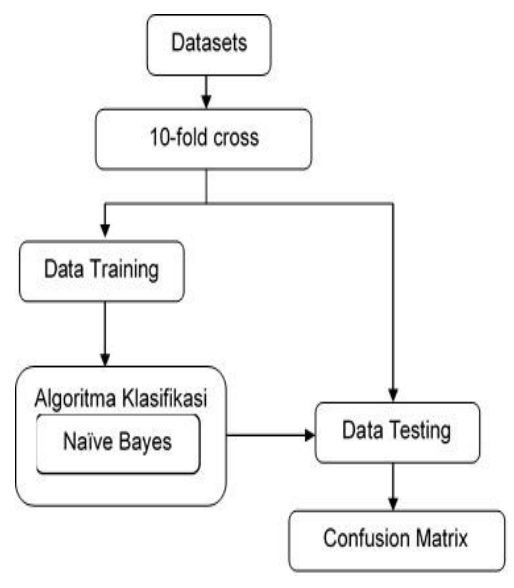

Gambar 1. Rancangan penelitian

Datasets (Gambar 2) berisi atribut sebagai berikut: nim, gelombang, wilayah, umur, semester, nama jurusan, kuliah sambil kerja, jadwal kerja, waktu kuliah, ip semester 1 , ip semester 2 , ip semester 3 , ip semester 4, ip semester 5, indeks prestasi komulatif, melaksanakan tugas akhir.

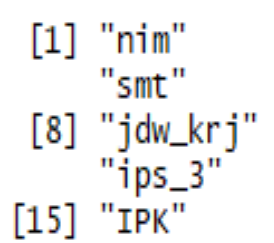

$$
\begin{aligned}
& \text { "gel" } \\
& \text { "nm_jrs" } \\
& \text { "waktu" } \\
& \text { "ips_4" } \\
& \text { "TA" }
\end{aligned}
$$

$$
\begin{aligned}
& \text { "wi1" } \\
& \text { "k1h_smb1_krj" } \\
& \text { "ips_1" } \\
& \text { "ips_5" }
\end{aligned}
$$

Gambar 2. Atribut datasets

Dari data mahasiswa tersebut dijabarkan tipe data (Gambar 3) dari masing-masing atribut yang ada hal tersebut diperlukan agar nantinya data dapat diukur dengan menggunakan rumus dari algoritma yang sudah ada.

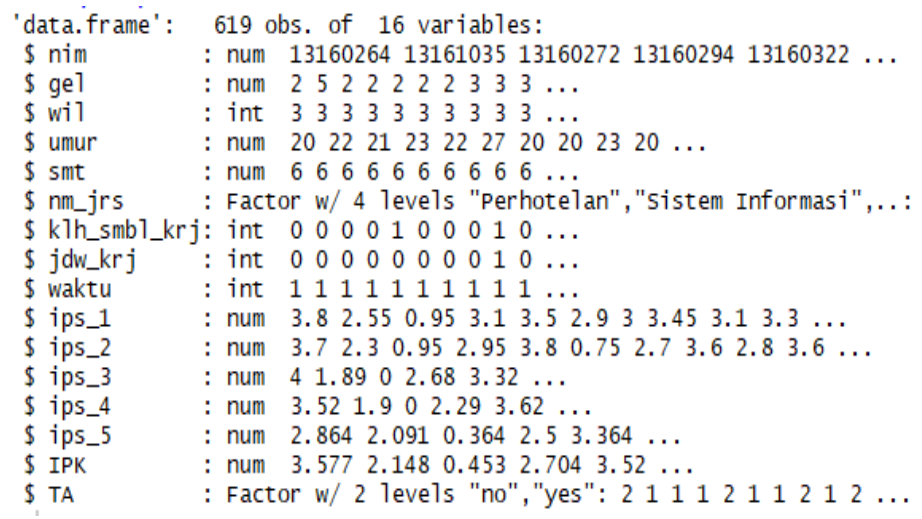

Gambar 3. Tipe data masing-masing atribut

Setelah data disiapkan kemudian data di-cleaning terlebih dahulu dengan mengecek kekosongan data dalam atribut, karena dataset yang disediakan tidak ada yang kosong atau missing maka proses langsung pada tahap validasi data dengan teknik 10 -fold cross validation seperti disajikan pada Gambar 4 yang membagi 
dataset menjadi training sebesar $70 \%$ dan testing sebesar $30 \%$.

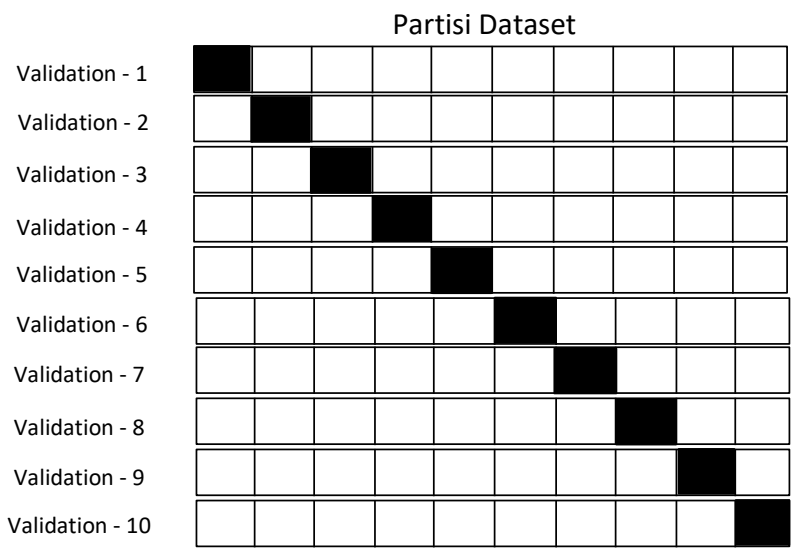

\section{Gambar 4. Stratified 10-fold Cross Validation}

Penggunaan software Rapid Miner dengan cara mengimpor informasi dari sumber database untuk diperiksa dan dianalisa. Selanjutnya, data yang dibagi menjadi data training tersebut berjumlah 433 data komponen nya bisa dilihat dari Gambar 5 berikut ini:

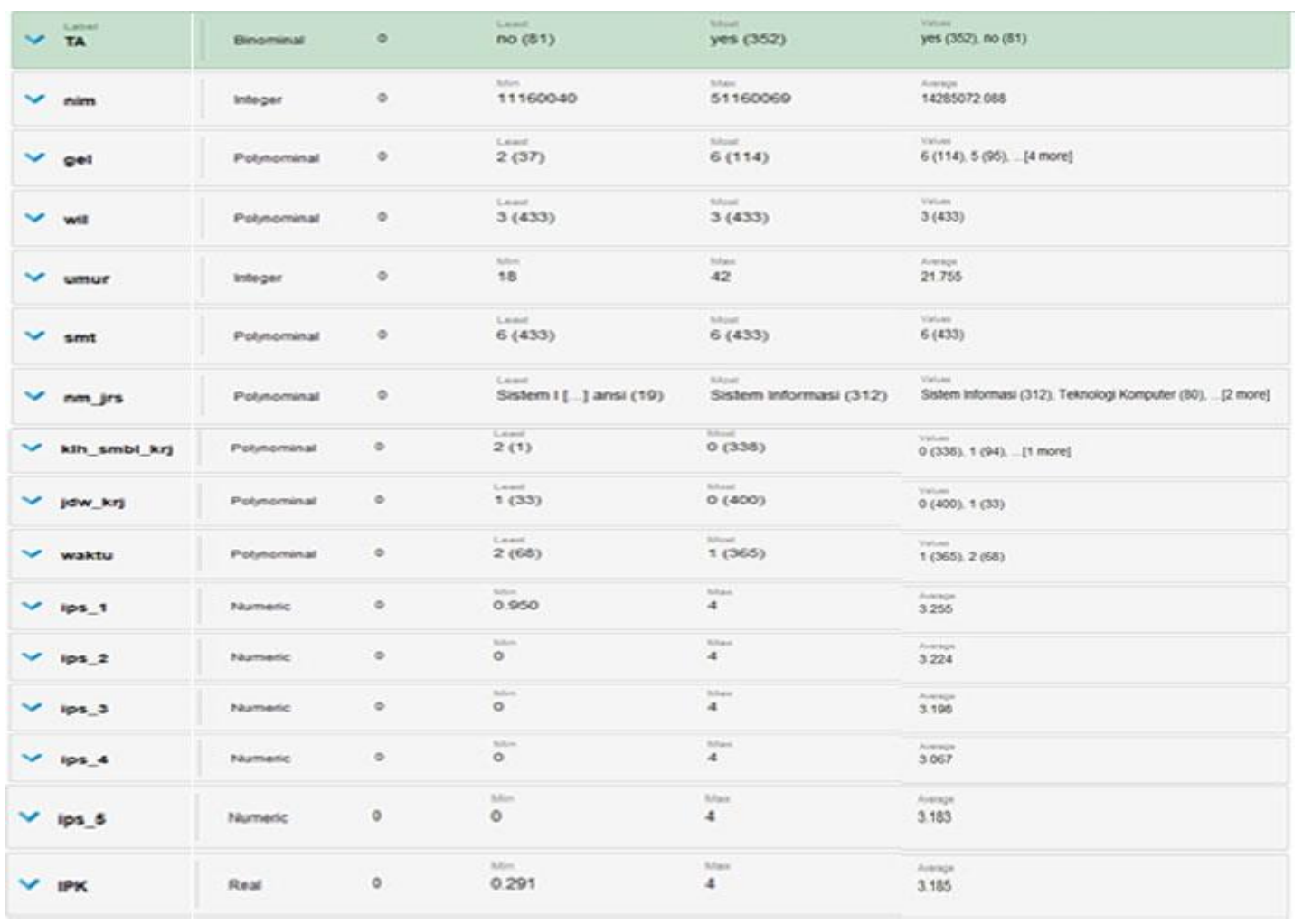

Gambar 5. Statistik data training

Dari dari data training diterapkanlah algoritma Naïve Bayes kemudian dibandingkan dengan data testing sehingga didapatkan prediksi probabilitasnya yang bisa dilihat di Tabel 2 confusion matrix. 
Tabel 2. Hasil Confusion Matrix

\begin{tabular}{ccc}
\hline & Actual Yes & Actual No \\
\hline Predicted Yes & 156 & 0 \\
Predicted No & 7 & 21 \\
\hline
\end{tabular}

Accuracy $=\frac{156+21}{156+0+7+21}=96,24 \%$

$$
\text { Recall }=\frac{156}{156+0}=100 \%
$$$$
\text { Precision }=\frac{156}{156+7}=95,76 \%
$$

Pengukuran evaluasi pada data mining dengan studi kasus nilai akademik mahasiswa yaitu dengan mengukur akurasi dan perhitungan akurasi berdasarkan confusion matrix. Dilihat dari Tabel 2. Hasil confusion matrix, di mana nilai TP (true positive) adalah jumlah data yang diprediksi benar dan kenyataanya juga benar, nilai TB (true negative) adalah jumlah data yang diprediksi salah dan kenyataannya salah. FP (false positive) adalah jumlah data yang diprediksi benar tapi kenyataanya salah, sedangkan FN (false negative) adalah jumlah data yang diprediksi salah tapi kenyataanya benar. Tabel 2 menunjukkan model Naïve Bayes, pada hasil perhitungan nya bisa dilihat bahwa model distribusi nilai class "yes" sebesar 0,813 sedangkan class "no" sebesar 0,187.

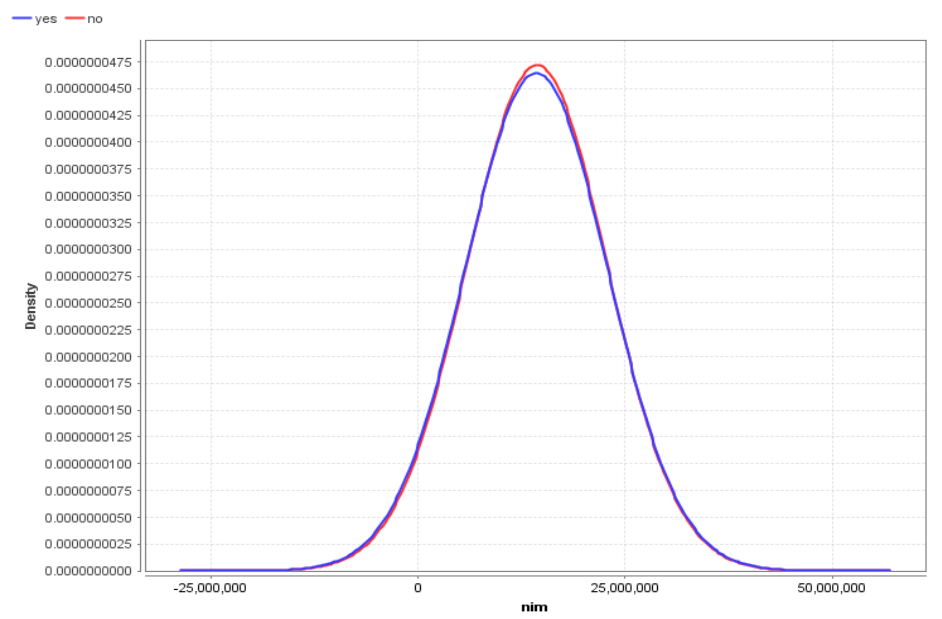

Gambar 6. Sample Distribution Naïve Bayes

Hasil klasifikasi yang didapat kemudian dihitung nilai accuracy, precision, dan recall. Berdasarkan perhitungan pada table confusion matrix maka accuracy $96,24 \%$, precison $95,76 \%$, dan recall $100 \%$. 


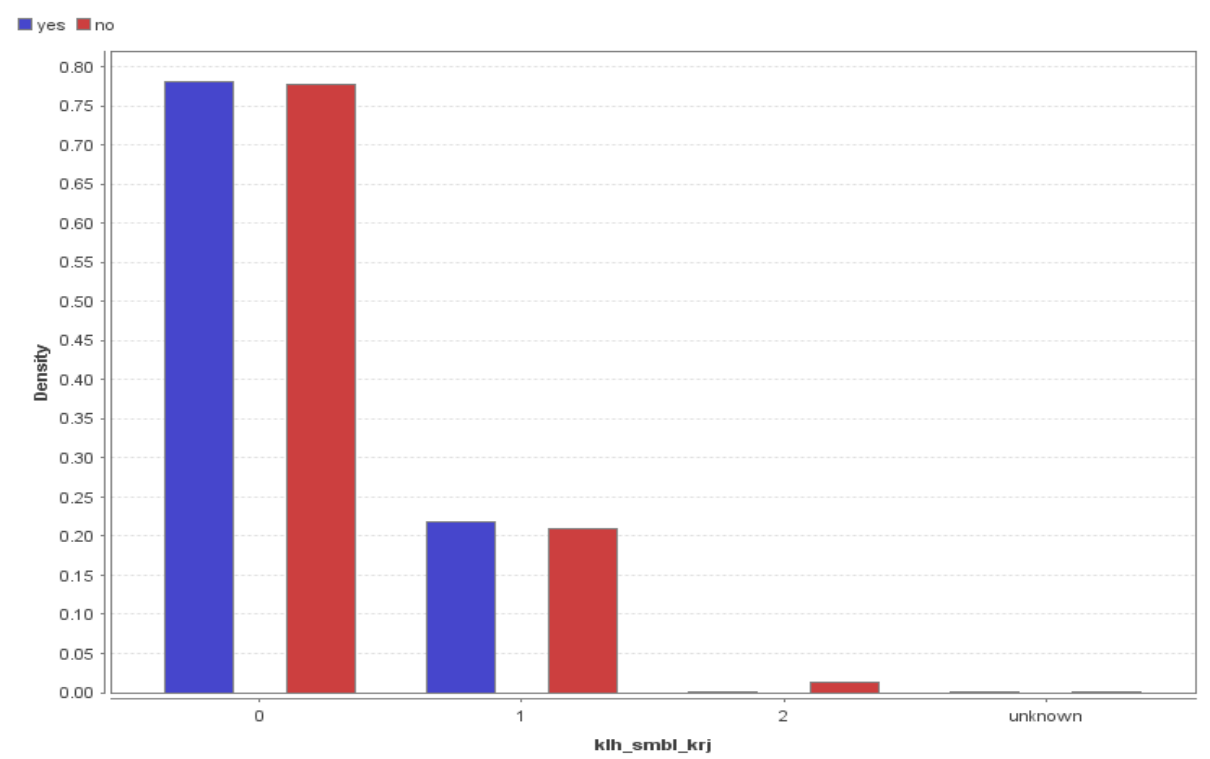

Gambar 7. Berdasarkan Mahasiswa Kuliah sambil Kerja

Gambar 7 menunjukkan mahasiswa yang terdaftar TA dilihat dari status mahasiswa sambil bekerja bahwa yang tidak bekerja maupun yang bekerja jumlah yang terdaftar TA sama besar.

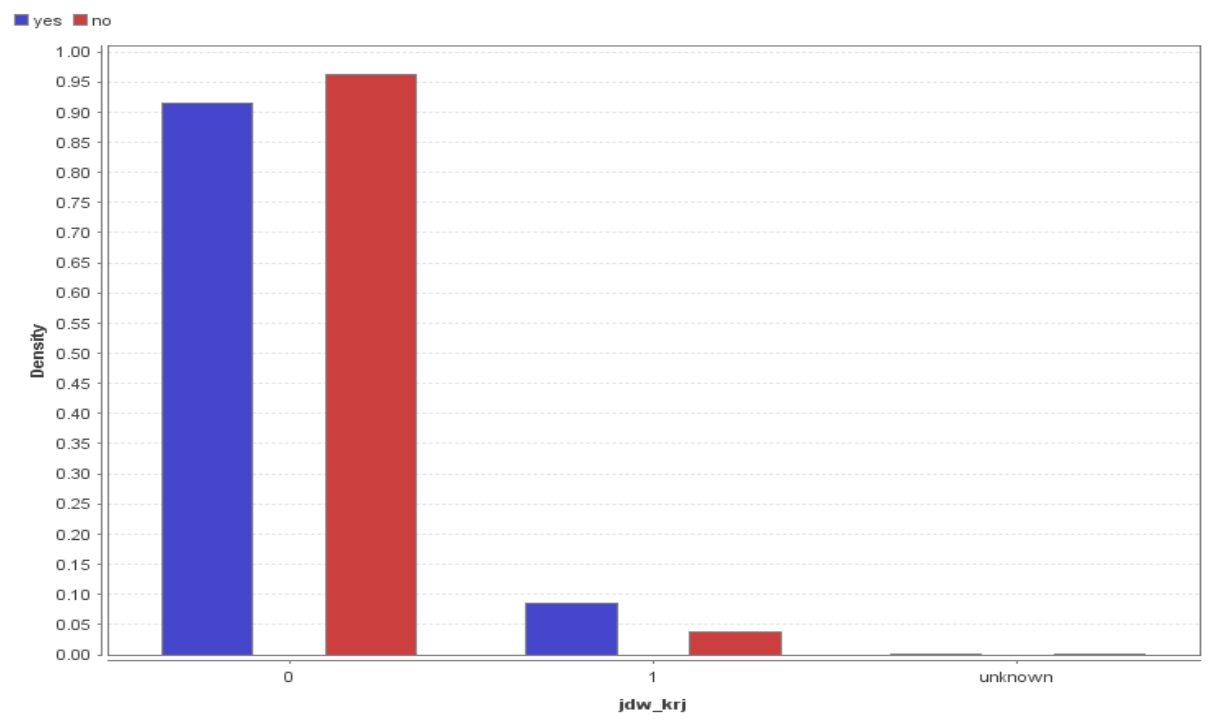

Gambar 8. Berdasarkan jadwal kerja mahasiswa

Berdasarkan Gambar 8 menunjukkan bahwa yang tidak bekerja dan tidak terdaftar TA lebih banyak daripada yang tidak bekerja terdaftar TA.
Kemudian yang jadwal bekerja pagi terdaftar TA lebih banyak dari pada yang tidak terdaftar TA. 


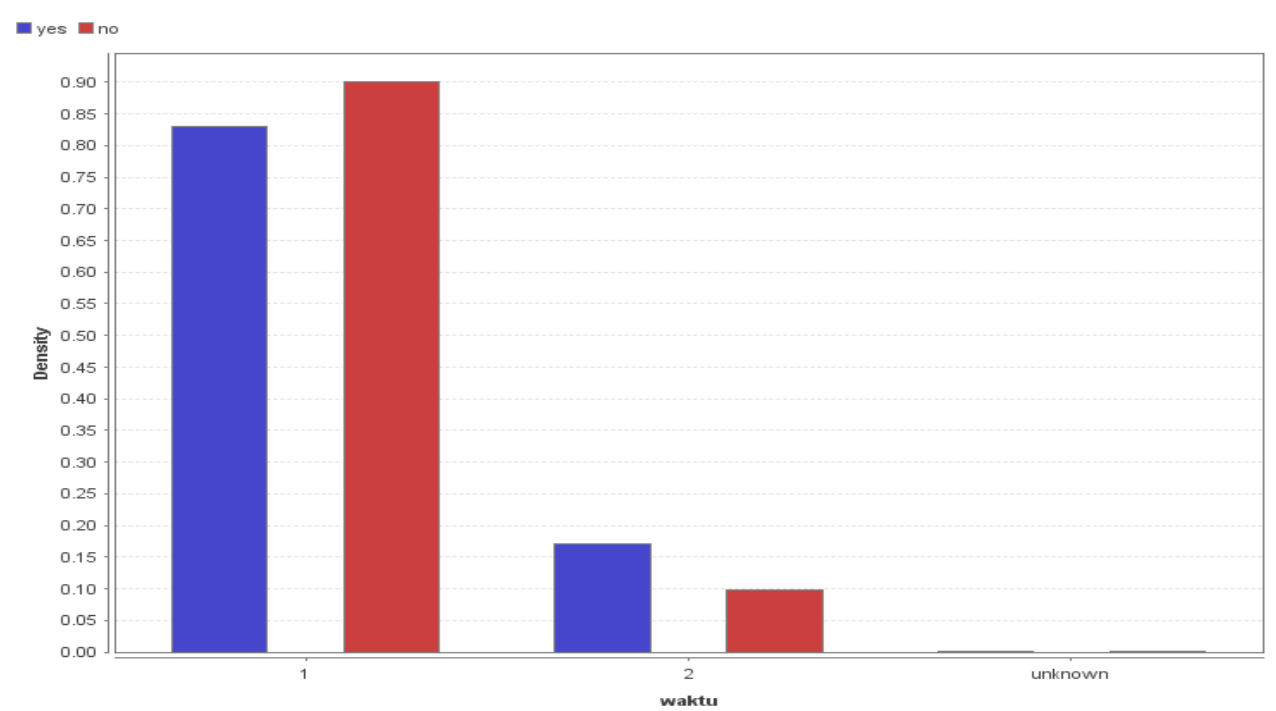

Gambar 9. Berdasarkan waktu kuliah

Gambar 9 menunjukkan bahwa yang kuliah pagi banyak yang tidak terdaftar TA sedangkan yang kuliah sore banyak yang terdaftar TA.

\section{SIMPULAN}

Penelitian ini menggunakan data mahasiswa Universitas Bina Sarana Informatika wilayah 3 yaitu kampus BSI wilayah jawa tengah. Dengan menggunakan algoritma Naïve Bayes untuk memprediksi mengukur nilai akademis mahasiswa dengan menggunakan algoritma Naïve Bayes dimana memanfaatkan perhitungan probabilitas dan statistik data sebelumnya untuk memprediksi data di masa depan berdasarkan pada data sebelumnya. Berdasarkan tabel confusion matrix hasil penelitian menunjukkan accuracy $96,24 \%$, precison $95,76 \%$, dan recall $100 \%$. Selain itu dengan algoritma Naïve Bayes menunjukkan hasil prediksi berdasarkan mahasiswa yang kuliah sambil bekerja, jadwal kerja mahasiswa, dan berdasarkan waktu kuliah.

\section{UCAPAN TERIMAKASIH}

Terima kasih kepada Universitas Bina Sarana Informatika yang telah menyediakan waktu untuk penelitian dan data sebagai sample penelitian dan terima kasih juga kepada Universitas Pendidikan Ganesha yang telah memberi kesempatan sehingga artikel ilmiah ini dapat diterbitkan pada Jurnal Sains \& Teknologi.

\section{DAFTAR PUSTAKA}

Annisa, R. (2019). Analisis Komparasi Algoritma Klasifikasi Data Mining Untuk Prediksi Penderita Penyakit Jantung. Jurnal Teknik Informatika Kaputama. 3(1). 22-28.

Ayuwanti, Irma. 2016. Meningkatkan Aktivitas Dan Hasil Belajar Matematika Menggunakan Model Pembelajaran Kooperatif Tipe Group Investigation Di Smk Tuma'ninah Yasin Metro. Jurnal Sap. 1(2). 105-114.

Brown, M. S. 2014. Data Mining For Dummies. Wiley Publishing Inc. United States.

Bunker, R. P., \& Thabtah, F. (2019). A Machine Learning Framework For Sport Result Prediction. Applied Computing And Informatics, 15(1), 27-33.

Hamsa, H., Indiradevi, S., \& Kizhakkethottam, J. J. (2016). Student Academic Performance Predicting Model Using Decision Tree And Fuzzy Genetic Algorithm. Procedia Technology, 25, 326-332.

Guney, Yilmaz. 2009. "Exogenous and Endogenous Factors Influencing Students' Performance in Undergraduate Accounting Modules", Accounting Education: an International Journal. 18(1). 51-73.

Maulana, Gun Gun. 2017. Pembelajaran Dasar Algoritma Dan Pemrograman 
Menggunakan El-Goritma Berbasis

Web . Jurnal Teknik Mesin (JTM). 6(2). 69-73.

Mandelman, S. D., Barbot, B., \& Grigorenko, E. L. 2015. Predicting Academic Performance And Trajectories From A Measure Of Successful Intelligence. Learning And Individual

Differences. 51. 387-393

Miguéis, V. L., Freitas, A., Garcia, P. J. V, \& Silva, A. 2018. Early Segmentation Of Students According To Their Academic Performance: A Predictive Modeling Approach. Decision Support Systems. 115.36-51

Sirait, Erlando Doni. 2016. Pengaruh Minat Belajar Terhadap Prestasi Belajar Matematika . Jurnal Formatif 6(1): 35-43.

Wijaya, Anggita Langgeng. 2012. Pengaruh Tingkat Partisipasi Kelas Terhadap Kinerja Akademik Mahasiswa . Jurnal Ekonomi \& Pendidikan. 9(1). 124-132. 